\title{
Histopathological and clinical features of nodular lymphocyte-predominant Hodgkin lymphoma and their impact on prognosis: first report from Iran
}

\author{
Ahmad Monabati ${ }^{1}$ - Akbar Safaei ${ }^{1} \cdot$ Maral Mokhtari $^{1} \cdot$ Pardis Nematollahi $^{2} \cdot$ Marjan Faghih $^{3}$. \\ Samaneh Boroumand-Noughabi ${ }^{1}$ (D)
}

Received: 29 April 2020 / Accepted: 27 July 2020 / Published online: 31 July 2020

(C) Springer-Verlag GmbH Germany, part of Springer Nature 2020

\begin{abstract}
Nodular lymphocyte-predominant Hodgkin lymphoma (NLPHL) is a rare subtype of Hodgkin lymphoma (HL). It shows different histoarchitectural patterns which are reported to be of prognostic significance. This study aimed to investigate the clinicopathological features of NLPHL cases in Shiraz, Iran, and their possible impact on prognosis. Between March 2014 and November 2019, all records for lymphoma were extracted from the electronic files of hospitals affiliated with Shiraz University of Medical Sciences. The slides of all NLPHL cases were extracted and reviewed. Other necessary data was retrieved from hospital records and through direct contact with patients. Among1168 lymphoma cases, 382 were HLs and 19.1\% (73) of them were of the NLPHL type. The median age of NLPHL patients was 34 years. Of the patients, $51.5 \%$ showed variant patterns, and $11 \%$ of them had BM involvement. The variant morphology was significantly associated with BM involvement $(p=0.02)$. Patients with higher stage tumors had lower OS and PFS rates. Stage, BM involvement, and infra-diaphragmatic involvement were significantly associated with outcomes. The rate of NLPHL and variant morphology seems to be high in our center in Iran. The variant morphology was associated with a higher BM involvement rate but not with OS or PFS. Higher stage, BM, and subdiaphragmatic disease involvement were associated with worse outcomes.
\end{abstract}

Keywords Nodular lymphocyte-predominant Hodgkin lymphoma · NLPHL · Hodgkin lymphoma · Architectural pattern · Prognosis

\section{Introduction}

Hodgkin lymphoma (HL) accounts for $15-25 \%$ of malignant lymphomas $[1,2]$. About $5 \%$ of HL cases are reportedly of the nodular lymphocyte-predominant Hodgkin lymphoma (NLPHL) type [2-4]. Unlike the classic subtypes of HL, NLPHL lacks the classical Hodgkin Reed-Sternberg cells

Samaneh Boroumand-Noughabi

Samaneh.Boroumand@gmail.com

1 Department of Pathology, Faculty of Medicine, Shiraz University of Medical Sciences, Shiraz, Iran

2 Department of Pathology, Faculty of Medicine, Isfahan University of Medical Sciences, Isfahan, Iran

3 Department of Biostatistics, School of Medicine, Arak University of Medical Sciences, Arak, Iran
(HRS). Instead of HRS, NLPHL is characterized by a characteristic kind of neoplastic cell called lymphocyte-predominant (LP) cells. These cells do not express CD15 or CD 30, but they do express B cell markers, including CD20 [3]. Epidemiologic, morphologic, and immunophenotypic features of NLPHL are summarized in Table 1.

NLPHL affects mostly males in their 4th decade of life and follows a favorable prognosis in most cases. It is generally a localized disease with an indolent clinical course; however, some cases present with advanced disease characterized by marrow and spleen involvement as well as B symptoms [3]. NLPHL shows variable histoarchitectural growth patterns. Fan et al. in 2003 reported six morphologic patterns in NLPHL patients (Table 2) [6]. It has been reported that there are correlations between growth patterns and the clinical course of the disease [7-10].

To the best of our knowledge, there is no report from Iran addressing the histoarchitectural or other clinicopathological 
Table 1 Common epidemiologic, morphologic, and immunophenotypic features of nodular lymphocyte-predominant Hodgkin lymphoma [3, 5]

\begin{tabular}{ll}
\hline Epidemiology & Accounts for about 5-10\% of Hodgkin lymphomas \\
& Predominantly affects males \\
& Most patients are aged between 30 and 50 years \\
Morphology & $\begin{array}{l}\text { Neoplastic cells are called lymphocyte-predominant (LP) cells which have popcorn-like } \\
\text { folded nuclei. LP cells are mostly located in the center of reactive B cell nodules and are } \\
\text { rimmed by a rosette of T follicular helper cells. }\end{array}$ \\
Immunophenotype & LP cells: CD20+, OCT2+, CD75+, CD79a+, BOB1+, PAX5+, CD45+, BCL6+, CD10-, \\
& EMA+(50\%), CD15-, CD30- \\
T follicular helper cells rosette: PD1(CD279)+, CD57+, BCL6+
\end{tabular}

aspects of NLPHL or their prognostic effects. The current study aimed to find the relative prevalence of NLPHL, the frequency of its different morphologic growth patterns, and the effects of its clinicopathological features on survival and prognosis at hospitals affiliated with Shiraz University of Medical Sciences, Shiraz, Iran. Shiraz University of Medical Sciences is regarded as a referral center in southern Iran.

\section{Materials and methods}

\section{Patients and clinical data}

The current study was conducted at the Hematopathology Center of Shiraz University of Medical Sciences, Shiraz, Iran. Between March 2014 and March 2019, all records for lymphoma were extracted from the electronic files of hospitals affiliated with Shiraz University of Medical Sciences. The relative prevalence of NLPHL between Hodgkin lymphomas and other types of lymphomas was calculated. Other data including age, gender, primary location of the tumor, stage, BM involvement, treatment information, recurrence, and survival were retrieved from hospital records and through direct contact with patients when needed. The study protocol was approved by the Research Ethics Committee of Shiraz University of Medical Sciences (IR.SUMS.MED.REC.1398.466).

\section{Morphology and immunohistochemistry review}

The immunohistochemistry (IHC) and hematoxylin and eosin (H\&E) slides of all NLPHL cases were extracted from the pathology archives. To confirm the diagnosis of NLPHL CD20, CD30, CD15, CD3, and PD1 slides were reviewed. In some cases, CD57, PAX5, OCT2, BOB1, CD23, and LMP1 stains were also available. LP cells were positive for CD20 and negative for CD15, and CD30. PAX5, OCT2, and BOB1 were helpful in some difficult cases. Rosetting T cells were positive for CD3 and PD1. In challenging cases, CD57,
Table 2 Immunoarchitectural patterns of nodular lymphocytepredominant Hodgkin lymphoma according to Fan et al. [3, 6]

\begin{tabular}{|c|c|c|}
\hline \multicolumn{2}{|l|}{ Pattern } & \multirow{2}{*}{$\begin{array}{l}\text { Description } \\
\text { Classic nodular pattern, B cell-rich: LP cells are mostly located inside the nodules } \\
\text { of small non-neoplastic B cells. LP cells are surrounded by a rim of reactive } \\
\text { CD57/PD1-positive T cells }\end{array}$} \\
\hline ypical & A & \\
\hline & B & $\begin{array}{l}\text { Serpiginous/interconnected nodular pattern: similar to pattern A. The only difference is that B } \\
\text { cell nodules are interconnected }\end{array}$ \\
\hline \multirow[t]{4}{*}{ Variant } & $\mathrm{C}$ & $\begin{array}{l}\text { Nodular with prominent extra-nodular L\&H (LP) Cells: LP cells are frequently located outside } \\
\text { the nodules. The background is predominantly composed of reactive T cells as well as small } \\
\text { nodules of reactive B cells. LP cells outside the nodules may be surrounded by } \\
\text { CD57/PD1(+/-) T cells }\end{array}$ \\
\hline & D & $\begin{array}{l}\text { Nodular with T cell-rich background: The nodules are mostly composed of reactive } \mathrm{T} \text { cells with } \\
\text { few reactive B cells. LP cells are surrounded by a rim of reactive CD57/PD1-positive T cells }\end{array}$ \\
\hline & $\mathrm{E}$ & $\begin{array}{l}\text { Diffuse pattern (T cell-rich B cell lymphoma-like): LP cells are in a diffuse background of } \\
\text { reactive T cells and may be surrounded by CD57/PD1(+/-) T cells. Presence of at least } \\
\text { one B cell nodule containing LP cells is necessary to rule out T cell/histiocyte-rich large } \\
\text { B cell lymphoma }\end{array}$ \\
\hline & $\mathrm{F}$ & $\begin{array}{l}\text { (Diffuse), "moth-eaten" with B cell-rich background: The background is predominantly com- } \\
\text { posed of reactive B cells. There are small areas of reactive T cells giving a moth-eaten } \\
\text { appearance to the background. LP cells are surrounded by a rim of reactive } \\
\text { CD57/PD1-positive T cells }\end{array}$ \\
\hline
\end{tabular}


CD4, and CD8 staining were also available [3, 5].The cases were subtyped morphologically based on CD20 and/or PAX5, CD3, PD1, and/or CD57stained slides into six patterns (A to F), according to Fan's categorization (Table 2) [5, 6]. In cases exhibiting a minor pattern, if the minor and major patterns were in the same category (both were in typical or variant categories), the case was subtyped according to the major pattern. If there was a minor or major component of variant pattern while the other pattern was typical, according to Hartmann et al. [7], these cases were classified based on their variant pattern. Then they were reclassified as classic (patterns $\mathrm{A}$ and $\mathrm{B}$ ) and variant (patterns $\mathrm{C}$ to $\mathrm{F}$ ) types. To differentiate NLPHL from $T$ cell/histiocyte-rich large B cell lymphoma, immunostaining for PD1, CD20, CD3, CD4, and CD8 was used. If there was at least one small $\mathrm{B}$ cell nodule containing LP cells, the case was diagnosed as NLPHL. This criterion was present in all cases with $\mathrm{D}$ or $\mathrm{E}$ patterns. In addition, the presence of PD1-positive T cell rosettes surrounding LP cells was regarded in favor of NLPHL. Dominance of CD8positive $\mathrm{T}$ cells at the stroma was also considered in favor of $\mathrm{T}$ cell/histiocyte-rich large B cell lymphoma [5].

\section{Statistical analysis}

Fisher's exact and chi-square tests were used to check the relationship between category variables. The Mann-Whitney $U$ test was used to examine the differences in mean ages with variables in the two groups. The Shapiro-Wilk test was employed to assess normality, and Levene's test was used for homogeneity of variances. Univariate analysis was conducted by univariate Cox regression for the influence of age, gender, stage, BM involvement, pattern, and subdiaphragmatic involvement on overall survival (OS) and progression-free survival (PFS) times. Variables with significant or borderline significant values $(p \leq .10)$ in the univariate analysis were entered the Cox model for multiple analyses. All analyses were performed using the SPSS statistical software, version 22. $p$ values less than 0.05 were considered statistically significant.

\section{Results}

Between March 2014 and November 2019, 1168 cases of lymphoma were diagnosed in hospitals affiliated with Shiraz University of Medical Sciences, Shiraz, Iran. Among these cases, 382 (32.7\%) were Hodgkin lymphomas. NLPHL accounted for $19.1 \%(n=73)$ of the Hodgkin lymphomas. The median age of 73 NLPHL patients was 34 years (ranging between 3 and 74) with a mean of $36.33 \pm 14.59$ years. There was no significant difference in age between male and female subjects ( $35.35 \pm 13.19$ vs. $38.59 \pm 16.15$, respectively, $p=$ 0.39 ). The majority of patients were male $(69.9 \%)$. Eight cases (11\%) showed BM involvement, and in 3 of these cases, BM was the primary site of disease presentation (Fig. 1). The median follow-up time was 25 (ranging between 1 and 62) months. At 5 years, the estimation of overall survival was 85\%. All cases displayed morphologic and immunophenotypic features characteristic of NLPHL, confirming the original diagnosis. After slide review, 7 cases were excluded from further analysis because of incomplete data, most notably due to small sample size which was not enough to be classified in a morphological pattern subtype. In the remaining cases, 3 (4.7\%) of non-BM samples were core needle biopsies and the other nonBM samples $(n=61,95.3 \%)$ were excisional biopsies.

Clinical and demographic characteristics of patients are summarized in Table 3. Sixty percent of tumors were located primarily in the cervical and axillary lymph nodes. There were 5 cases with extranodal primary sites. Two of them were located in the bone marrow, and the others were located in the thigh, submandibular, and retroperitoneal soft tissues. Most patients (66.7\%) received chemotherapy plus radiotherapy as primary treatment (Table 3). Different chemotherapy regimens (ABVD, CHOP, or CVP) were used, generally including rituximab. Three patients needed salvage therapy who received chemotherapy based (ICE or DHAP) regimens. Pattern A of Fan et al.'s classification was the most frequent pattern (40.9\%). Variant morphology was identified in $51.5 \%$ of patients. Seventeen cases
Fig. 1 Bone marrow involvement by NLPHL in one of the cases. a and $\mathbf{b}$ The H\&E slide shows lymphocytic aggregates in $\mathrm{BM}$ containing LP cells $(\times 40$ and $\times$ 400 , respectively). c Large CD20positive LP cells are seen $(\times 200)$. $\mathbf{d}$, e, and $\mathbf{f}$ Background lymphocytes are mostly CD4-positive $\mathrm{T}$ cells $(\times 40, \times 40$, and $\times 200$, respectively). This feature is in favor of NLPHL rather than T cell/ histiocyte-rich large B cell lymphoma

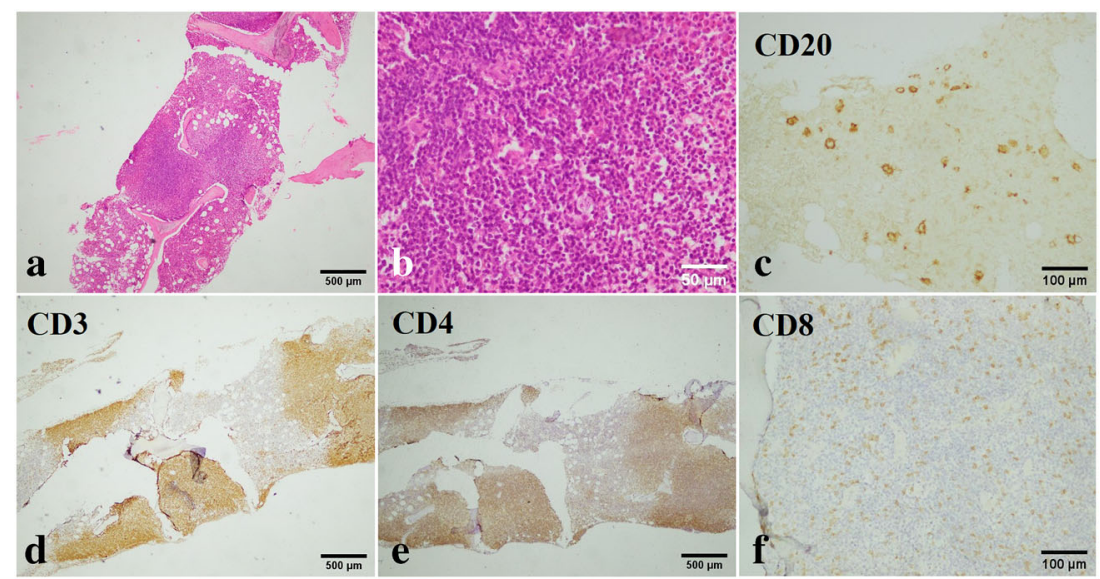


Table 3 Clinical, histological, and demographic characteristics of patients

\begin{tabular}{|c|c|c|}
\hline Variable & Categories & Mean $\pm \mathrm{SD}$, or $n(\%)$ \\
\hline Age (years) & - & $36.56 \pm 15.22$ \\
\hline \multirow[t]{2}{*}{ Gender } & Female & $20(30.3)$ \\
\hline & Male & $46(69.7)$ \\
\hline \multirow[t]{6}{*}{ Immunoarchitectural Pattern } & A & $27(40.9)$ \\
\hline & $\mathrm{B}$ & $5(7.6)$ \\
\hline & $\mathrm{C}$ & $19(28.8)$ \\
\hline & $\mathrm{D}$ & $3(4.5)$ \\
\hline & $\mathrm{E}$ & $12(18.2)$ \\
\hline & $\mathrm{F}$ & $0(0)$ \\
\hline \multirow[t]{2}{*}{ Histoarchitectural Pattern } & Typical & $32(48.5)$ \\
\hline & Variant & $34(51.5)$ \\
\hline \multirow[t]{6}{*}{ Primary Site } & Neck LN & $18(27.3)$ \\
\hline & Axillary LN & $24(36.4)$ \\
\hline & $\mathrm{BM}$ & $2(3)$ \\
\hline & Submandibular LN & $3(4.5)$ \\
\hline & Inguinal LN & $6(9.1)$ \\
\hline & Others & $13(19.7)$ \\
\hline \multirow[t]{2}{*}{ Subdiaphragmatic involvement } & Supra-diaphragmatic & $50(75.8)$ \\
\hline & Infra-diaphragmatic & $16(24.2)$ \\
\hline \multirow[t]{2}{*}{ BM involvement } & Not involved & $60(90.9)$ \\
\hline & BM involved & $6(9.1)$ \\
\hline \multirow[t]{4}{*}{ Ann Arbor Stage } & I & $43(65.2)$ \\
\hline & II & $12(18.2)$ \\
\hline & III & $6(9.1)$ \\
\hline & IV & $5(7.6)$ \\
\hline \multirow[t]{3}{*}{ Outcome } & Dead & $4(8.8)$ \\
\hline & $\begin{array}{l}\text { Alive with recurrence } \\
\text { or progression }\end{array}$ & $7(15.5)$ \\
\hline & $\begin{array}{l}\text { Alive with no recurrence } \\
\text { or progression }\end{array}$ & $34(75.5)$ \\
\hline \multirow[t]{4}{*}{ Treatment } & Not treated & $4(8.9)$ \\
\hline & Radiotherapy & $2(4.4)$ \\
\hline & $\begin{array}{l}\text { Chemotherapy } \\
\text { and radiotherapy }\end{array}$ & $30(66.7)$ \\
\hline & Chemotherapy & $9(20)$ \\
\hline Survival time (months) & - & $26.92 \pm 17.43$ \\
\hline
\end{tabular}

showed a minor pattern as well. In 13 of them, the minor and major patterns were in the same category (both were in typical or variant categories). These cases were subtyped according to the major pattern. In 4 of them, there was a minor or major component of variant pattern, while the other pattern was typical. These cases were classified based on their variant pattern. Pattern A was the most common pattern identified in cervical lymph nodes, while in axillary lymph nodes pattern $\mathrm{C}$ was more common (Table 4). Sequential biopsies were available in 3 patients. One of them showed diffuse large B cell lymphoma (DLBCL) in the relapsed sample.
Table 4 Primary site of the disease in relation to morphological patterns

\begin{tabular}{llrrrrr}
\hline Primary site & \multicolumn{7}{l}{ Morphological pattern } \\
\cline { 2 - 7 } & A & B & C & D & E & F \\
\hline Neck LN & 9 & 2 & 4 & 1 & 2 & 0 \\
Axillary LN & 7 & 3 & 10 & 2 & 2 & 0 \\
BM & 0 & 0 & 1 & 0 & 1 & 0 \\
Submandibular LN & 1 & 0 & 0 & 0 & 2 & 0 \\
Inguinal LN & 3 & 0 & 0 & 0 & 3 & 0 \\
Others & 7 & 0 & 4 & 0 & 2 & 0 \\
\hline
\end{tabular}


Fig. 2 Pattern A

immunoarchitecture in one of the cases. a and $\mathbf{b}$ The H\&E slide shows LP cells within nodular aggregates $(\times 100$ and $\times 400$, respectively). c PAX5 staining reveals the background is mostly composed of small B cells in a nodular fashion $(\times 40)$. $\mathbf{d}$ and $\mathbf{e}$ CD20 staining highlights large LP cells located in reactive $B$ cell nodules $(\times 100$ and $\times 400$, respectively). $\mathbf{f} \mathrm{LP}$ cells are surrounded by CD57-positive T follicular helper cells $(\times 400)$

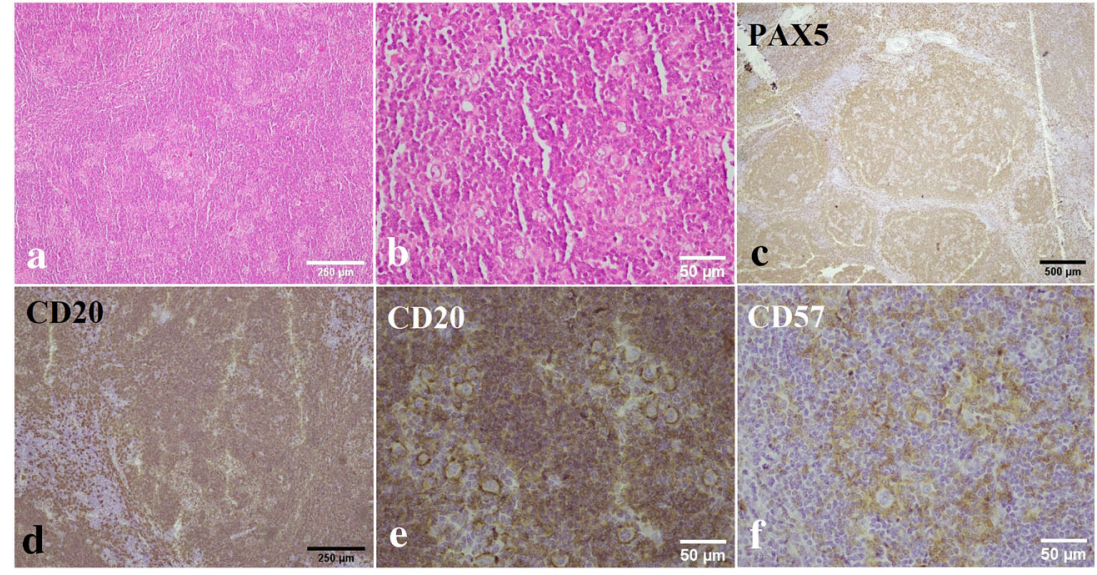

Figures 2 and 3 demonstrate findings in NLPHL with "typical (Pattern A)" and "variant (Pattern C)" morphologies.

The relationship between histoarchitectural patterns (typical versus variant) and other demographic and clinical characteristics of patients are shown in Table 5. There was a significant association between BM involvement and histoarchitectural pattern $(p=0.025)$. All patients with BM involvement exhibited variant morphology. Two (33\%) of them showed pattern $\mathrm{C}$ and $4(66.6 \%)$ exhibited pattern E. Patients with BM involvement had a younger age than those who did not $(26.33 \pm 20.94$ vs. $37.58 \pm 14.37$, respectively, $p=0.05$ ).

The univariate and multiple Cox regression analyses for the influence of age, gender, BM involvement, histoarchitectural pattern, stage, treatment, and subdiaphragmatic involvement on overall survival (OS) and progression-free survivals (PFS) are presented in Tables 6 and 7. The univariate analysis for overall survival time revealed that age, gender, BM involvement, histoarchitectural pattern, treatment, and subdiaphragmatic involvement are not significant risk factors for death at the level of 0.1 (all $p>0.1$ ). Tumors with higher stages (III and IV) had lower survival rates than others $(\mathrm{HR}=11.17, p=0.038$ for univariate and $\mathrm{HR}=9.79, p=0.05$ for multiple Cox regression analysis) (Table 6, Fig. 4). After entering multiple Cox regression for adjustments histoarchitectural pattern showed no significant correlation with overall survival (Table 6, Fig. 5).

After adjustment for other variables, age ( $\mathrm{HR}=0.95, p=$ $0.04)$ and stage $(H R=14.08, p=0.03)$ showed a significant correlation with PFS (Table 7). No significant correlation was found between histoarchitectural pattern and PFS (Table 7, Fig. 5).

The relationship between stage, subdiaphragmatic, and BM involvement with outcome is shown in Table 8. There are significant associations between disease stage, subdiaphragmatic, and $\mathrm{BM}$ involvement with outcome variables.

\section{Discussion}

Among the 1168 lymphoma cases involved in the current study, $32.7 \%(n=382)$ of them were Hodgkin lymphomas. NLPHL accounted for $19.1 \%$ of the Hodgkin lymphomas. NLPHL is reported to account for 3-8\% of HLs in Western
Fig. 3 Pattern C

immunoarchitecture in one of the cases. a and b The H\&E slide shows LP cells located mostly outside of the nodular structures ( $\times 100$ and $\times 400$, respectively). c The background contains a large number of CD3-positive $T$ cells $(\times 400)$. $\mathbf{d}$ and $\mathbf{e}$ There are small nodules of reactive $B$ cells, but LP cells are frequently located outside of the nodules ( $\times 40$ and $\times$ 400 , respectively). f Some LP cells are rimmed by PD1-positive follicular T helper cells $(\times 400)$

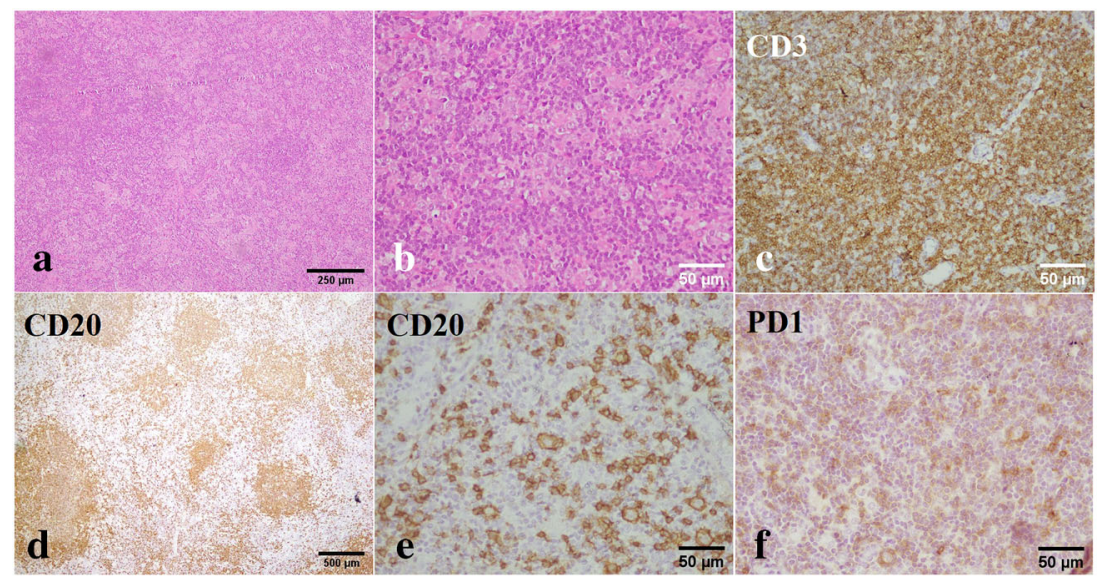


Table 5 Baseline characteristics of patients between two groups of histoarchitectural pattern

\begin{tabular}{|c|c|c|c|c|}
\hline & & $\begin{array}{l}\text { Typical } \\
(n=32)\end{array}$ & $\begin{array}{l}\text { Variant } \\
(n=34)\end{array}$ & $\begin{array}{l}p \\
\text { value }\end{array}$ \\
\hline Age (years) & & $38.31 \pm 13.39$ & $34.91 \pm 16.8$ & $0.6^{\mathrm{a}}$ \\
\hline Gender & $\begin{array}{l}\text { Female } \\
\text { Male }\end{array}$ & $\begin{array}{l}12(37.5) \\
20(62.5)\end{array}$ & $\begin{array}{l}8(23.5) \\
26(76.5)\end{array}$ & $0.22^{\mathrm{b}}$ \\
\hline \multirow[t]{5}{*}{ Primary site } & $\begin{array}{l}\text { Neck LN } \\
\text { Axillary LN }\end{array}$ & $\begin{array}{l}11(34.4) \\
10(31.3)\end{array}$ & $\begin{array}{l}7(20.6) \\
14(41.2)\end{array}$ & $0.64^{\mathrm{c}}$ \\
\hline & $\mathrm{BM}$ & $0(0)$ & $2(5.9)$ & \\
\hline & Submandibular LN & $1(3.1)$ & $2(5.9)$ & \\
\hline & Inguinal LN & $3(9.4)$ & $3(8.8)$ & \\
\hline & Others & $7(21.9)$ & $6(17.6)$ & \\
\hline $\begin{array}{c}\text { Subdiaphragmatic } \\
\text { involvement }\end{array}$ & $\begin{array}{l}\text { Supra-diaphragmatic } \\
\text { Infra-diaphragmatic }\end{array}$ & $\begin{array}{l}26(81.3) \\
6(18.8)\end{array}$ & $\begin{array}{l}24(70.6) \\
10(29.4)\end{array}$ & $0.31^{\mathrm{b}}$ \\
\hline Stage & $\begin{array}{l}\text { Low stage (I and II) } \\
\text { High stage (III and IV) }\end{array}$ & $\begin{array}{l}29(90.6) \\
3(9.4)\end{array}$ & $\begin{array}{l}26(76.5) \\
8(23.5)\end{array}$ & $0.12^{\mathrm{b}}$ \\
\hline \multirow[t]{3}{*}{ Outcome } & Dead & $1(4.5)$ & $3(13)$ & $0.26^{\mathrm{c}}$ \\
\hline & $\begin{array}{l}\text { Alive with recurrence or } \\
\text { progression }\end{array}$ & $2(9.1)$ & $5(21.7)$ & \\
\hline & $\begin{array}{l}\text { Alive with no recurrence or } \\
\text { progression }\end{array}$ & $19(86.4)$ & $15(65.2)$ & \\
\hline BM involvement & $\begin{array}{l}\text { Not involved } \\
\text { BM involved }\end{array}$ & $\begin{array}{l}32(100) \\
0(0)\end{array}$ & $\begin{array}{l}28(82.4) \\
6(17.6)\end{array}$ & $0.025^{\mathrm{c}}$ \\
\hline
\end{tabular}

${ }^{\text {a }}$ Mann-Whitney $U$ test

${ }^{\mathrm{b}}$ Chi-square test

${ }^{\mathrm{c}}$ Fisher's exact test countries $[1-3,11]$. Its incidence is even lower in Asian countries $[12,13]$. In a study reported in 2014 from our center, $9 \%$ of HLs were of NLPHL type [14]. Mozaheb et al. studied 391 lymphoma cases in Mashhad, Iran, and reported that $6.3 \%$ of their HLs were NLPHL [15]. In another study from Iran conducted by Shamloo et al. on 513 head and neck lymphoma cases, $200 \mathrm{HLs}$ were identified, 24 (12\%) of which were of the NLPHL type [16]. The higher incidence of NLPHL in the current study compared with studies from other countries as well as previous reports from Iran can be explained by various

Table 6 Univariate and multiple Cox regression analysis (overall survival)

\begin{tabular}{|c|c|c|c|c|c|c|c|}
\hline \multirow[t]{2}{*}{ Variable } & & \multicolumn{3}{|l|}{ Univariate } & \multicolumn{3}{|l|}{ Multiple } \\
\hline & & Hazard ratio (HR) & $95 \% \mathrm{CI}$ for $\mathrm{HR}$ & $p$ value & Hazard ratio (HR) & $95 \% \mathrm{CI}$ for $\mathrm{HR}$ & $p$ value \\
\hline Age & - & 0.98 & $(0.91-1.06)$ & 0.67 & & & \\
\hline \multirow[t]{2}{*}{ Gender } & Female & 0.03 & $(0-1032)$ & 0.52 & & & \\
\hline & Male & 1 & & & & & \\
\hline \multirow[t]{2}{*}{$\mathrm{BM}$ involvement } & Not involved & 0.38 & $(0.04-3.67)$ & 0.4 & & & \\
\hline & $\mathrm{BM}$ involved & 1 & & & & & \\
\hline \multirow[t]{2}{*}{ Histoarchitectural pattern } & Typical & 0.33 & $(0.03-3.17)$ & 0.34 & 0.49 & $(0.05-4.89)$ & 0.54 \\
\hline & Variant & 1 & & & 1 & & \\
\hline \multirow[t]{2}{*}{ Stage } & Low stage (I and II) & 1 & & & 1 & & \\
\hline & High stage (III and IV) & 11.17 & $(1.15-108.99)$ & 0.038 & 9.79 & $(0.98-98.1)$ & 0.05 \\
\hline \multirow[t]{2}{*}{ Treatment } & Not treated & 0.04 & $(0-6108.9)$ & 0.66 & & & \\
\hline & Received treatment & 1 & & & & & \\
\hline \multirow[t]{2}{*}{ Subdiaphragmatic involvement } & Supra-diaphragmatic & 0.35 & $(0.05-2.5)$ & 0.29 & & & \\
\hline & Infra-diaphragmatic & 1 & & & & & \\
\hline
\end{tabular}


Table 7 Univariate and multiple Cox regression analysis (progression-free survival)

\begin{tabular}{|c|c|c|c|c|c|c|c|}
\hline \multirow[t]{2}{*}{ Variable } & & \multicolumn{3}{|l|}{ Univariate } & \multicolumn{3}{|l|}{ Multiple } \\
\hline & & Hazard ratio (HR) & $95 \% \mathrm{CI}$ for $\mathrm{HR}$ & $p$ value & Hazard ratio (HR) & $95 \% \mathrm{CI}$ for $\mathrm{HR}$ & $p$ value \\
\hline Age & - & 0.95 & $(0.9-0.99)$ & 0.025 & 0.95 & $(0.91-0.99)$ & 0.038 \\
\hline \multirow[t]{2}{*}{ Gender } & Female & 1.55 & $(0.41-5.91)$ & 0.52 & & & \\
\hline & Male & 1 & & & & & \\
\hline \multirow[t]{2}{*}{ BM involvement } & Not involved & 1 & & & 1 & & \\
\hline & BM involved & 5.05 & $(1.43-17.89)$ & 0.012 & 7.65 & $(0.6-97.75)$ & 0.12 \\
\hline \multirow[t]{2}{*}{ Histoarchitectural pattern } & Typical & 0.39 & $(0.1-1.47)$ & 0.16 & 1.42 & $(0.24-8.29)$ & 0.69 \\
\hline & Variant & 1 & & & 1 & & \\
\hline \multirow[t]{2}{*}{ Stage } & Low stage (I and II) & 1 & & & 1 & & \\
\hline & High stage (III and IV) & 10.26 & $(2.65-39.73)$ & 0.001 & 14.08 & $(1.32-149.81)$ & 0.028 \\
\hline \multirow[t]{2}{*}{ Treatment } & Not treated & 0.04 & $(0-227.16)$ & 0.47 & & & \\
\hline & Received treatment & 1 & & & & & \\
\hline \multirow[t]{2}{*}{ Subdiaphragmatic involvement } & Supra-diaphragmatic & 1 & & & 1 & & \\
\hline & Infra-diaphragmatic & 9.86 & $(2.61-37.27)$ & 0.001 & 0.54 & $(0.03-11.06)$ & 0.69 \\
\hline
\end{tabular}

reasons. Recent publication of more precise diagnostic criteria for this entity may have led to better identification of this subtype, which may have caused its relative increased frequency. All the previously mentioned studies from Iran were published at least 3 to 4 years ago, and at that time NLPHL may have been under-diagnosed. It should be noted that in the most recent studies, NLPHL accounted for $12 \%$ of HLs which is similar to the current study [16]. Nevertheless, a recent increase in this lymphoma type cannot be excluded. Further studies are needed to confirm these results.

NLPHL mostly affects men in their 4th decade of life [3]. About $69.9 \%$ of patients in the current study were males, which is in line with other studies. In a study on 471 NLPHL cases, $75.8 \%$ of patients were males [17]. Similar results were reported by Molin et al. [18]. In another study reported by Eladl et al. from Japan, $64 \%$ of their NLPHL cases were males [12]. The median age of patients in the present study was 34 years (mean: $36.33 \pm$ 14.5). Similar results have been reported by other researchers, and the reported median ages range between 32 and 56 years [12, 17, 19-22]. One study reported a significantly older age in affected females compared with males ( 59 vs. $44, p=0.39$ ), but others (including the current one) did not find such differences [18].
Fig. 4 Kaplan-Meier curve for the relative OS of the high-stage (III and IV) and low-stage (I and II) groups of the NLPHL cases $(p=0.05)$

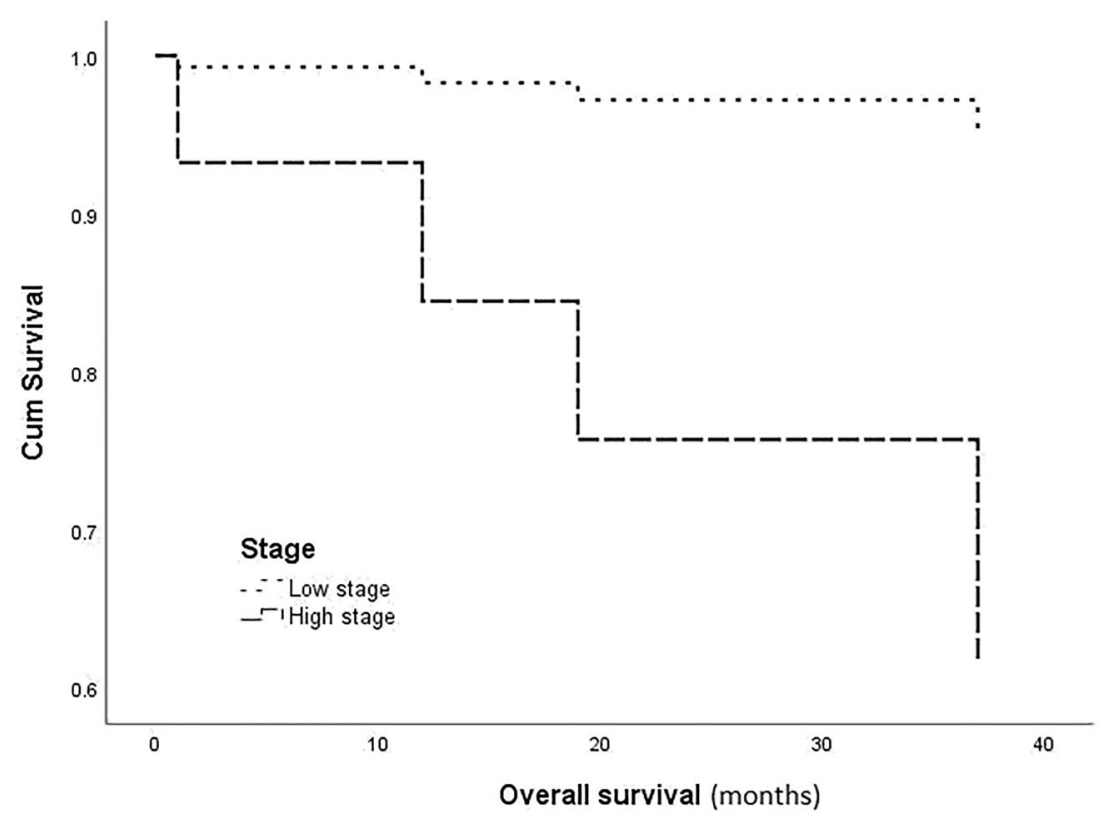




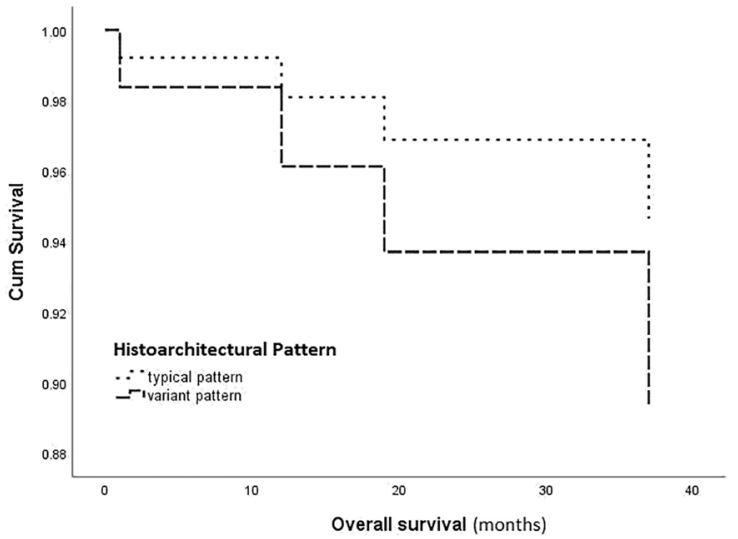

b

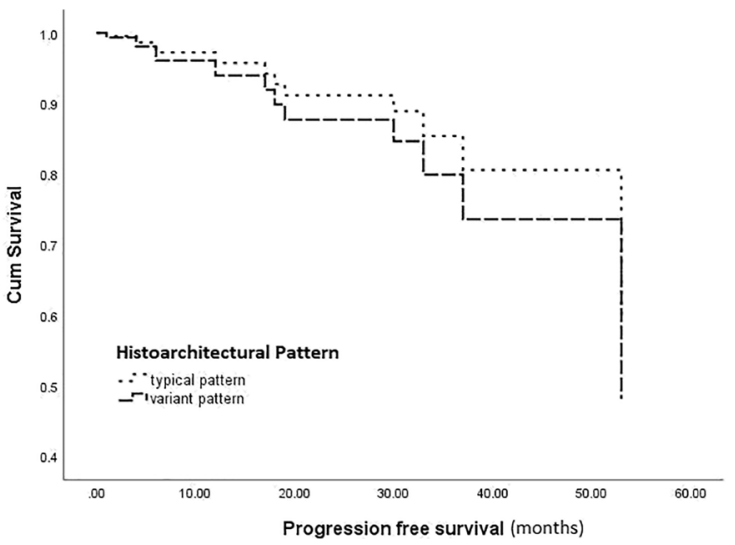

Fig. 5 a and b Kaplan-Meier curves for the relative PFS $(p=0.69)$ and OS $(p=0.54)$ of the cases with typical and variant NLPHL histoarchitectures

Regarding the histoarchitectural patterns, $48.5 \%$ of patients in this study showed a typical growth pattern, and the others were included in the variant group. Types A, C, and $\mathrm{E}$ of Fan's classification were the most prevalent types, respectively. The rate of typical morphology varies in different studies ranging between 47 and $78 \%$ [7, 8, 10, 23]. Some studies have reported a higher rate of typical morphology than the current results [8, 23]. Hartmann et al. studied 423 NLPHL cases and reported that $72 \%$ of their patients showed a typical morphological pattern [7]. Another study by Agbay et al. reported that $47 \%$ of their NLPHL cases showed the classic pattern, and the others had a variant morphology or a mixture of typical and variant morphology [10]. In a study by Hartmann et al., which considered 33 cases treated within the German Hodgkin Study Group (GHSG) and 41 cases treated outside the GHSG, the typical morphology was identified in $64 \%$ of cases inside the GHSG and $44 \%$ of those out of it [19]. The authors declared that because of the more complicated diagnosis, these patients had not been involved in the GHSG study [19]. To determine the exact rate of typical and variant morphologies in NLPHL, more studies on larger sample sizes are needed. In addition, as the patients with more difficulties in diagnosis do not usually enter clinical trials, studies that include all diagnosed cases are preferred rather than ones including a selected number of cases.

The current study found a significant association between variant morphology and BM involvement. All patients with BM involvement showed the variant morphology. No significant association was found between histoarchitectural patterns and OS, PFS, or patient outcome. Similarly, in a study by Panjwani et al., all cases with BM involvement showed variant morphology [9]. In line with the current study, Hartmann et al. found a significant association between variant morphology and advanced disease. They also reported a significant association between variant morphology and a higher relapse rate and introduced variant morphology as an independent prognostic factor [7]. Another study by Agbay et al. found that BM involvement by lymphoma in NLPHL patients is more common in variant morphology $(p=0.02)$, which is similar to the current results [10]. Hartmann et al.

Table 8 Fisher's exact test for the relationship between stage, subdiaphragmatic, and BM involvements with outcome of patients

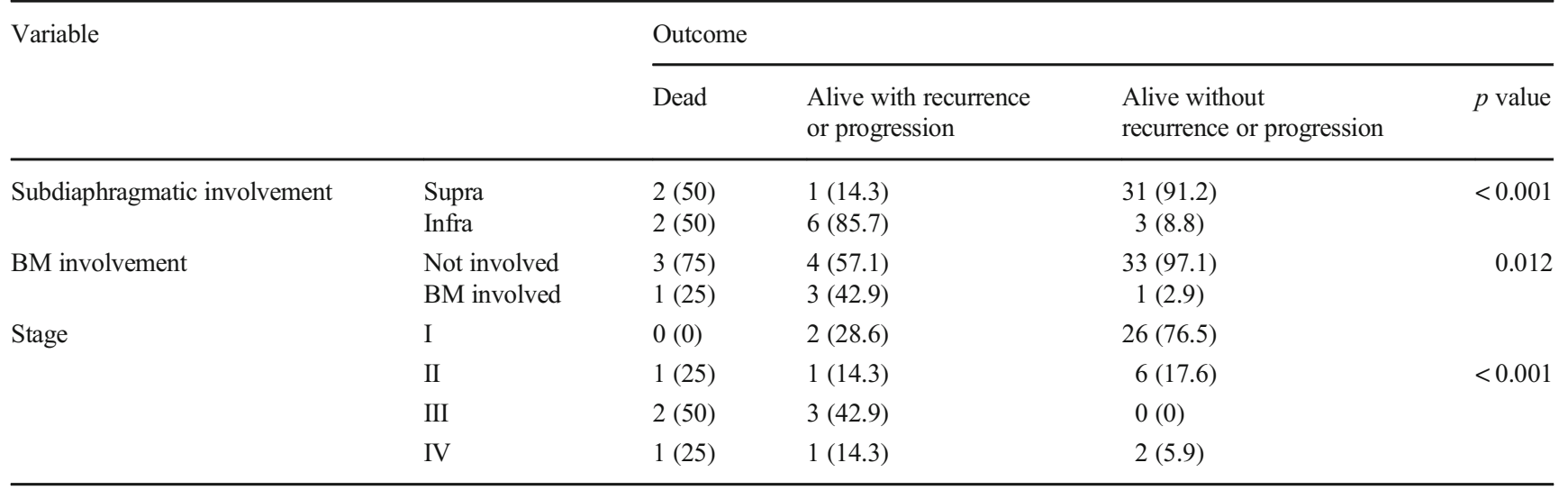


found that presentation in an advanced stage is more common in patients with variant morphology [19]. In addition, they found that time to relapse correlates with histoarchitectural growth patterns (5.2 vs. 2.8 for typical and variant morphologies, respectively) [19]. Other studies on childhood NLPHL have also reported lower rates of complete response, higher rates of relapse, higher rates of unfavorable presentation, and lower EFS in variant morphology compared with typical morphology [23, 24]. The absence of a significant association between survival and histoarchitectural patterns in the current study may be related to the limited sample size as well as the short follow-up period (median follow-up time $=25$ months). Furthermore, a limitation of the current study is that the patients did not receive uniform treatment and this may have influenced the results.

Several factors have been reported to affect the prognosis in NLPHL patients. In the current study, it was found that adverse outcome was associated with higher stages, BM involvement, and subdiaphragmatic disease involvement. In addition, patients with higher stage tumor (III and IV) showed lower OS and PFS rates. Eichenauer et al. studied 471 NLPHL cases and reported that PFS and OS were significantly related to BM and liver involvement. They also showed that OS was lower in advanced stage patients [17]. In line with the current results, Agbay et al. also found that disease progression and relapse were more frequent in patients with BM involvement [10]. Furthermore, the rate of BM involvement in the current study was $11 \%$ which is somewhat higher than reported elsewhere $[9,10]$. It may be explained by the influence of a higher proportion of variant morphology in this study. In addition, in $3(4.1 \%)$ cases in this study, the primary site of disease presentation was BM. To the best of our knowledge, such presentation has not been reported by others.

In conclusion, to the best of our knowledge, this is the first report from Iran on the histoarchitectural and clinical aspects of NLPHL. Higher frequencies of variant morphology as well as BM involvement were found compared with most other studies. The histoarchitectural patterns were associated with BM involvement but not with OS or PFS. Stage, BM involvement, and subdiaphragmatic involvement were significantly associated with outcome. Patients with higher stage tumors had lower OS and PFS rates.

Acknowledgments We gratefully acknowledge our colleagues from the laboratory of Shahid Faghihi Hospital as well as other hospitals affiliated with Shiraz University of Medical Sciences, Shiraz, Iran.

Authors' contribution All authors contributed to the study design. Data collection and analysis were performed by Ahmad Monabati, Akbar Safaei, Maral Mokhtari, Pardis Nematollahi, and Samaneh BoroumandNoughabi. Statistical analysis was done by Marjan Faghih. The first draft of the manuscript was written by Samaneh Boroumand-Noughabi, and all authors commented on the previous versions of the manuscript. All authors read and approved the final manuscript.
Funding information The study was supported by a grant from Shiraz University of Medical Sciences, Shiraz, Iran.

Data availability The datasets generated during the study are available in IBM SPSS format from the corresponding author on reasonable request.

\section{Compliance with ethical standards}

Competing interests The authors declare that they have no competing interests.

Ethical approval This study was performed in line with the principles of the Declaration of Helsinki. The study protocol was approved by the Research Ethics Committee in Shiraz University of Medical Sciences (IR.SUMS.MED.REC.1398.466).

\section{References}

1. Bazzeh F, Rihani R, Howard S, Sultan I (2010) Comparing adult and pediatric Hodgkin lymphoma in the surveillance, epidemiology and end results program, 1988-2005: an analysis of 21734 cases. Leuk Lymphoma 51:2198-2207

2. Thomas R, Re D, Zander T, Wolf J, Diehl V (2002) Epidemiology and etiology of Hodgkin's lymphoma. Ann Oncol 13:147-152

3. Hartmann S, Eichenauer DA (2020) Nodular lymphocyte predominant Hodgkin lymphoma: pathology, clinical course and relation to T-cell/histiocyte rich large B-cell lymphoma. Pathology 52:142153

4. Anagnostopoulos I, Hansmann M-L, Franssila K, Harris M, Harris NL, Jaffe ES, Han J, van Krieken J, Poppema S, Marafioti T, Franklin J, Sextro M, Diehl V, Stein H (2000) European task force on lymphoma project on lymphocyte predominance Hodgkin disease: histologic and immunohistologic analysis of submitted cases reveals 2 types of Hodgkin disease with a nodular growth pattern and abundant lymphocytes. Blood 96:1889-1899

5. Stein H, Swerdlow SH, Gascoyne RD, Poppema S, Jaffe ES, Pileri SA (2017) Nodular lymphocyte predominant Hodgkin lymphoma. In: Swerdlow SH, Campo E, Harris NL, Jaffe ES, Pileri SA, Stein $\mathrm{H}$, Thiele J (eds) WHO classification of Tumours of Haematopoietic and lymphoid tissues, revised, 4th edn. IARC, Lyon, pp 431-434

6. Fan Z, Natkunam Y, Bair E, Tibshirani R, Warnke RA (2003) Characterization of variant patterns of nodular lymphocyte predominant Hodgkin lymphoma with immunohistologic and clinical correlation. Am J Surg Pathol 27:1346-1356

7. Hartmann S, Eichenauer DA, Plütschow A, Mottok A, Bob R, Koch K, Bernd HW, Cogliatti S, Hummel M, Feller AC, Ott G, Möller P, Rosenwald A, Stein H, Hansmann ML, Engert A, Klapper W (2013) The prognostic impact of variant histology in nodular lymphocyte-predominant Hodgkin lymphoma: a report from the German Hodgkin Study group (GHSG). Blood 122: $4246-4252$

8. Shankar AG, Kirkwood AA, Hall GW, Hayward J, O'Hare P, Ramsay AD (2015) Childhood and adolescent nodular lymphocyte predominant Hodgkin lymphoma-a review of clinical outcome based on the histological variants. Br J Haematol 171:254-262

9. Panjwani P, Epari S, Sengar M, Laskar S, Menon H, Shet T (2015) Bone marrow involvement in nodular lymphocyte predominant Hodgkin lymphoma occurs in tumors with a variant pattern. Leuk lymphoma 56:236-238

10. Agbay RLMC, Loghavi S, Zuo Z, Fayad L, Dabaja B, Medeiros LJ, Khoury JD (2018) Bone marrow involvement in patients with 
nodular lymphocyte predominant Hodgkin lymphoma. Am J Surg Pathol 42:492-499

11. Colby TV, Hoppe RT, Warnke RA (1982) Hodgkin's disease: a clinicopathologic study of 659 cases. Cancer 49:1848-1858

12. Eladl AE, Satou A, Elsayed AA, Suzuki Y, Shimizu-Kohno K, Kato S, Tomita A, Kinoshita T, Nakamura S, Asano N (2015) Nodular lymphocyte predominant Hodgkin lymphoma: clinicopathological study of 25 cases from Japan with a reappraisal of tissue associated macrophages. Pathol Int 65:652-660

13. Yang Q-P, Zhang W-Y, Yu J-B, Zhao S, Xu H, Wang W-Y, Bi CF, Zuo Z, Wang XQ, Huang J, Dai L, Liu WP (2011) Subtype distribution of lymphomas in Southwest China: analysis of 6,382 cases using WHO classification in a single institution. Diagn Pathol 6:77

14. Monabati A, Safaei A, Noori S, Mokhtari M, Vahedi A (2016) Subtype distribution of lymphomas in south of Iran, analysis of 1085 cases based on World Health Organization classification. Ann Hematol 95:613-618

15. Mozaheb Z, Aledavood A, Farzad F (2011) Distributions of major sub-types of lymphoid malignancies among adults in Mashhad, Iran. Cancer Epidemiol 35:26-29

16. Shamloo N, Ghannadan A, Jafari M, Ahmadi S, Mortazavi H, Baharvand M (2017) Head and neck lymphoma in an Iranian population. Iran J Otorhinolaryngol 29:261

17. Eichenauer DA, Plütschow A, Fuchs M, Sasse S, Baues C, Böll B, von Tresckow B, Diehl V, Borchmann P, Engert A (2020) Longterm follow-up of patients with nodular lymphocyte-predominant Hodgkin lymphoma treated in the HD7 to HD15 trials: a report from the German Hodgkin Study Group. J Clin Oncol 38:698-705

18. Molin D, Linderoth J, Wahlin BE (2017) Nodular lymphocyte predominant Hodgkin lymphoma in Sweden between 2000 and 2014: an analysis of the Swedish Lymphoma Registry. Br J Haematol 177:449-456

19. Hartmann S, Plütschow A, Mottok A, Bernd HW, Feller AC, Ott G, Cogliatti S, Fend F, Quintanilla-Martinez L, Stein H, Klapper W,
Möller P, Rosenwald A, Engert A, Hansmann ML, Eichenauer DA (2019) The time to relapse correlates with the histopathological growth pattern in nodular lymphocyte predominant Hodgkin lymphoma. Am J Hematol 94:1208-1213

20. Shivarov V, Ivanova M (2018) Nodular lymphocyte predominant Hodgkin lymphoma in USA between 2000 and 2014: an updated analysis based on the SEER data. Br J Haematol 182:727-730

21. Posthuma HL, Zijlstra JM, Visser O, Lugtenburg PJ, Kersten MJ, Dinmohamed AG (2020) Primary therapy and survival among patients with nodular lymphocyte-predominant Hodgkin lymphoma: a population-based analysis in the Netherlands, 1993-2016. Br J Haematol 189:117-121

22. Borchmann S, Joffe E, Moskowitz $\mathrm{CH}$, Zelenetz AD, Noy A, Portlock CS, Gerecitano JF, Batlevi CL, Caron PC, Drullinsky P, Hamilton A, Hamlin PA Jr, Horwitz SM, Kumar A, Matasar MJ, Moskowitz AJ, Owens CN, Palomba ML, Younes A, Straus DJ (2019) Active surveillance for nodular lymphocyte-predominant Hodgkin lymphoma. Blood 133:2121-2129

23. Prasad M, Narula G, Chinnaswamy G, Arora B, Shet T, Panjwani P, Sengar M, Laskar S, Khanna N, Banavali S (2018) Unfavorable presentation but comparable outcome: presentation and outcome of children with nodular lymphocyte predominant Hodgkin lymphoma from India. Pediatr Blood Cancer 65:e27288

24. Untanu RV, Back J, Appel B, Pei Q, Chen L, Buxton A, Hodgson DC, Ehrlich PF, Constine LS, Schwartz CL, Hutchison RE (2018) Variant histology, IgD and CD30 expression in low-risk pediatric nodular lymphocyte predominant Hodgkin lymphoma: a report from the Children's Oncology Group. Pediatr Blood Cancer 65: e26753

Publisher's note Springer Nature remains neutral with regard to jurisdictional claims in published maps and institutional affiliations. 